\title{
Comparative efficacy of different treatment regimens against bovine mastitis caused by Staphylococcus aureus
}

\author{
Krupa Rose Jose ${ }^{1}$, K. Vijayakumar ${ }^{2}$, K. Justin Davis ${ }^{3}$, V. H. Shyma ${ }^{3}$, and R. Ambily ${ }^{4}$ \\ Department of Veterinary Epidemiology and Preventive Medicine, \\ College of Veterinary and Animal Sciences, Mannuthy, Thrissur-680651, Kerala, \\ Kerala Veterinary and Animal Sciences University, Pookode, Wayanad, India.
}

\begin{abstract}
Citation: Jose, K. R., Vijayakumar, K., Justin, D. K., Shyma, V. H. and Ambily, R. 2021. Comparative efficacy of different treatment regimens against bovine mastitis caused by Staphylococcus aureus. J. Vet. Anim. Sci. 52(1) : 55-59.

DOI: https://doi.org/10.51966/jvas.2021.52.1.55-59
\end{abstract}

Received : 24.11 .2020

Accepted: 10.12 .2020

Published: 01.01.2021

\begin{abstract}
Bovine mastitis is an endemic disease among dairy cattle all over the world and antimicrobial therapy is one of the prime therapeutic and prophylactic tool against mastitis. In the present scenario, the efficacy of antimicrobial chemotherapy is being threatened by the rising tide of antimicrobial resistance. A study was conducted to evaluate the comparative clinico-therapeutic efficacy of three selected antimicrobial protocols among 21 animals with clinical mastitis, from which S. aureus could be isolated. Therapeutic trials were conducted with Inj. Ceftriaxone (10 mg/ $\mathrm{kg}$ body weight BID) for five days in group I, Inj. Ceftriaxone-sulbactam (6 mg/kg IV BID for five days) in group II and Inj. Sulphadiazine-trimethoprim (15 mg/kg IV BID for five days) in group III. The bacteriological cure was assessed by streaking the milk samples collected $24 \mathrm{~h}$ after termination of the treatment on to a bacteriological medium and the clinical cure was assessed by the return to normal colour and consistency of milk and remission of the pathological manifestations in udder. All the treatment groups had exhibited an excellent bacteriological cure rate as evident from the 100 per cent post treatment culture negative samples. The group I exhibited 100 per cent clinical cure whereas, in group II and group II, the clinical cure was 87.5 per cent and 75 per cent respectively. Statistical analysis using Fisher's exact test revealed that there is no significant difference among the three treatment groups and all the treatment regimens are equally effective.
\end{abstract}

Keywords: Mastitis, ceftriaxone, ceftriaxone sulbactam, sulphadiazine trimethoprim, clinicotherapeutic efficacy

Mastitis, defined as the inflammation of the mammary gland parenchyma, continues to be a persistent problem in the dairy industry all over the globe, despite decades of novel treatment and

${ }^{*}$ Forms part of the MVSc thesis submitted by the first author to the Kerala Veterinary and Animal Sciences University, Pookode, Wayanad, Kerala.

1. MVSc Scholar and corresponding author:email:krupaputhuparampil@gmail.com, Ph: 8606719132

2. Professor and Head

3. Assistant Professors

4. Assistant Professor, Department of Veterinary Microbiology

Copyright: () 2021 Krupa et al. This is an open access article distributed under the terms of the Creative Commons Attribution 4.0 International License (http://creativecommons.org/licenses/by/4.0/), which permits unrestricted use, distribution, and reproduction in any medium, provided the original author and source are credited. 
control programmes. It engenders a negative impact on the economic status of farmers and ultimately jeopardises the national economy. In India the annual economic loss due to bovine mastitis had increased 135 folds in about almost 5 decades from INR 529 million/annum in 1962 (Dhanda and Sethi, 1962) to INR 71655.1 million/annum in 2009 (Bansal and Gupta, 2009). In addition, it also poses public health threat due to its potential for transmission of many zoonotic milk borne diseases, antibiotic residues, bacterial toxins as well as the organisms carrying numerous virulent and antimicrobial resistant genes. Targeted antimicrobial therapy plays an important role in mastitis control by reducing the level of herd infection and preventing new infections. Hence the present study was envisaged to detect the clinico-therapeutic efficacy of three selected antimicrobial protocols.

\section{Materials and methods}

The present study was conducted in 83 lactating dairy cows presented with clinical signs suggestive of mastitis. Milk samples were collected aseptically from each animal using separate sterile screw capped vials. Isolation of bacteria was attempted from individual quarter samples by direct streaking of the milk on to brain heart infusion agar (BHIA; M211, Himedia) followed by incubation of the plates at $37^{\circ} \mathrm{C}$ for
$24 \mathrm{~h}$. The isolates were identified based on morphological characterisation using Gram's staining, cultural characteristics on selective media and biochemical characterisation as per Barrow and Feltham (1993) and Quinn et al. (2013).

The isolates were then subjected to in vitro antibiotic susceptibility testing by Kirby Bauer disc diffusion assay (Bauer et al., 1966) as per the Clinical and Laboratory Standards Institute guidelines (CLSI, 2017). Antibiotic discs impregnated with known concentration of nine antimicrobial agents viz., amoxicillinsulbactam, ceftriaxone, ceftriaxone- sulbactam, cotrimoxazole, enrofloxacin, gentamicin, methicillin, penicillin $\mathrm{G}$ and tetracycline were used.

Twenty one animals with $\mathrm{CM}$ from which $S$. aureus isolates were obtained was divided into three different groups with a minimum of six animals in each group using random number generation. Each group was administered three different antimicrobial protocols as shown in Table. 1 based on the results of in vitro drug sensitivity by disc diffusion method.

The rate of recovery was assessed based on clinical cure and bacteriological cure. The clinical manifestation of animal before and after treatment are shown in fig. For the

Table 1. Antimicrobial protocol used for treatment trial

\begin{tabular}{|c|c|c|}
\hline $\begin{array}{c}\text { Treatment } \\
\text { groups }\end{array}$ & Drug used & $\begin{array}{c}\text { Dose, route and duration of } \\
\text { treatment }\end{array}$ \\
\hline Group I & $\begin{array}{r}\text { Inj. Ceftriaxone } \\
\text { (Inj. Cefstan 3 g, Zoetis, India Ltd.) }\end{array}$ & $\begin{array}{r}10 \mathrm{mg} / \mathrm{kg} \text { body weight IV, } \\
\text { twice daily for five days }\end{array}$ \\
\hline Group II & $\begin{array}{r}\text { Inj. Ceftriaxone-sulbactam } \\
\text { (Inj. Safevet Forte 4.5 g, Boehringer Ingelheim, } \\
\text { India Pvt. Ltd.) }\end{array}$ & $\begin{array}{r}6 \mathrm{mg} / \mathrm{kg} \text { body weight IV, } \\
\text { tw }\end{array}$ \\
\cline { 2 - 3 } & twice daily for a period of five days \\
\hline
\end{tabular}

Table No 2. Statistical analysis of the three treatment trials

\begin{tabular}{|c|l|c|c|c|c|c|}
\hline \multirow{2}{*}{ Groups } & Antibiotic used & \multirow{2}{*}{$\begin{array}{c}\text { Number } \\
\text { of }\end{array}$} & \multicolumn{2}{|c|}{ Clinical cure } & \multicolumn{2}{c|}{ Bacteriological cure } \\
\cline { 5 - 7 } & & animals & Number & Per cent & Number & Per cent \\
\hline 1 & Ceftriaxone & 6 & 6 & 100 & 6 & 100 \\
\hline 11 & Ceftriaxone-sulbactam & 7 & 6 & 85.7 & 7 & 100 \\
\hline 111 & Sulphadiazine-trimethoprim & 8 & 6 & 75 & 8 & 100 \\
\hline \multicolumn{7}{|c|}{ Fisher's exact test: Exact two sided significance p value: 0.747} \\
\hline
\end{tabular}

56 Comparative efficacy of different treatment regimens against.. 


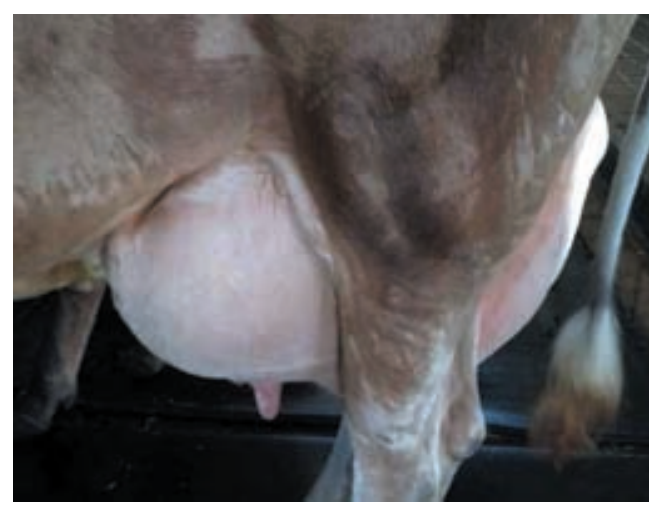

B. Before treatment

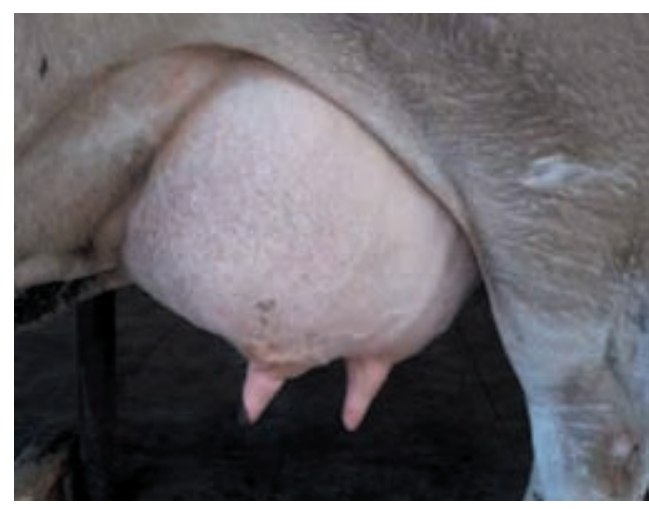

A. After treatment

Fig 1. Changes in clinical manifestation of animals before and after treatment

determination of the bacteriological cure, the quarter samples were collected aseptically in sterile vials $24 \mathrm{~h}$ after the completion of antibiotic therapy and was subjected to isolation to see the presence of any bacteria. The results of the clinico - therapeutic efficiency between three treatment groups were compared using by Fisher's exact test with the help of IBM - SPSS version 24.0.

\section{Results and discussion}

Out of the 83 quarter samples examined, 57 samples were positive in culture, of which five had mixed infection with two different bacterial isolates there by accounting for a total of 67 bacterial isolates. Of these isolates, the coagulase negative Staphylococci (CNS) predominated (40.29 per cent) followed by $S$. aureus (32.84 per cent), Micrococci (11.94 per cent) Klebsiella spp. (7.40 per cent), E. coli (4.47 per cent) and Streptococci (2.9 per cent). This was in accordance with previous studies by Kulangara et al. (2017) who reported 50 per cent prevalence of CNS from dry bovine udder whereas it was substantially higher when compared to Sebastian (2001) and Rathish (2014) who isolated 6.4 per cent and 23.81 per cent of CNS from all bacterial isolates.

The in vitro antimicrobial susceptibility testing by disc diffusion assay revealed that irrespective of the genus, majority of the isolates were found resistant to penicillin and methicillin whereas ceftriaxone and ceftriaxone-sulbactam were reported to be sensitive towards majority of the isolates. This was in concordance with the previous findings by Amrithapriya (2019) and Rathish (2014) who analysed the in vitro antibiogram of bacterial isolates from bovine clinical mastitis in and around Thrissur district.

Among the six animals in group 1 which were treated Ceftriaxone, a bactericidal third generation cephalosporin, all the animals (100 per cent) exhibited clinical cure and bacteriological cure following a treatment period of five days. This was in accordance with Dasohari et al. (2017) who proved 100 per cent animal wise and quarter wise cure rate for bovine SCM following intramuscular administration of ceftriaxone. In contrast to these reports, a comparatively low clinical and bacteriological cure rate of 82.35 per cent and 66.66 per cent was reported by Charaya et al. (2015) among buffaloes treated with ceftriaxone. This may be due to the disparity in innate immunity between different species of animals, which in turn influences the invasiveness, intracellular penetration and colonisation of mastitis pathogens.

The development and prevalence of bacterial resistancetoceftriaxone, oneofthemost widely used broad spectrum third generation cephalosporin, has been documented in recent years due to the production of beta lactamases (Xin et al., 2013). In order to combat these beta lactamase producing bacterial strains, ceftriaxone sulbactam was selected, in which cephalosporins are combined with the beta lactamase inhibitor sulbactam, which could irreversibly inhibit the hydrolytic action of beta lactamases and restore the activity of ceftriaxone 
against beta lactamase-producing bacteria. Seven cases of staphylococcal mastitis were treated with ceftriaxone - sulbactam at a dose rate of six milligram per kilogram body weight IV twice daily for a period of five days. The clinical cure was 85.7 per cent whereas all the animals had a bacteriological cure. The results were similar to Singh et al., 2015 who reported 84.61 per cent recovery rate from mastitis following therapy with ceftriaxone-tazobactam. However, Akova (2008) analyzed the in vitro and clinical efficacy of different beta lactamase inhibitors and concluded that sulbactam is the least potent inhibitor of this class compared to tazobactam and clavulanate.

Sulphadiazine-trimethoprim, a potentiated folate inhibitor was used to treat eight cases of CM in group III animals and it was found that all the cases had a bacteriological cure following the treatment period of five days whereas, only 75 per cent had clinical cure with the oedema of udder and reduction in milk yield being persisting even after the treatment course for two out of the eight cases treated. This was in accordance with Kalmus et al. (2011), who reported that 96.6 per cent susceptibility of $S$. aureus isolates to sulphadiazine-trimethoprim based on in vitro antibiogram. This higher per cent of sensitivity could be attributed to the mutual potentiation of activity between each drug that enhances its therapeutic efficacy (Mac Diarmid, 1978). However, based on in vivo pharmacokinetic studies in mid or late lactation dairy cows, Kaartinen et al. (1999), reported that the effectiveness of sulphadiazine-trimethoprim in maintaining adequate therapeutic concentrations in milk against mastitis pathogens appears to be unsatisfactory. This incongruity might be due to qualitative nature of in vitro assay that does not consider the host factors that contributes to the clinical cure or lack of in vitro susceptibility breakpoint data specific for mastitis (Kasravi et al. 2010).

A statistical analysis of the clinicotherapeutic efficacy of the three selected antimicrobial protocols using Fischer's exact test revealed that all three protocols were equally effective against contagious mastitis with no significant difference in their clinicotherapeutic efficacy ( $p$ value 0.747 ). In the present study, prompt treatment based on the findings of in vitro antibiogram and proper management of the underlying factors together with the efficacy of the antibacterial may have enhanced the clinical and bacteriological cure. The figure 1. shows the variation of clinical manifestations in the udder of animals before and after treatment. However, the absence of clinical cure even in culture negative samples of group II and group III could be attributed to the highly invasive and adaptable nature of $S$. aureus that enables them to survive and colonise deep inside the tissue.

\section{Conclusion}

The effectiveness of mastitis therapy depends on the nature of the aetiological agent, pathological changes in udder parenchyma, pharmacokinetics of antimicrobial agents, animalhusbandryactivitiesand timely veterinary intervention. Therefore, further scientific studies on the pharmacological effectiveness of various therapeutic regimens targeting a larger group of animals is warranted to develop an on farm herd level mastitis protocol that promotes judicious use of antimicrobials.

\section{Ethical approval and consent statement}

Oral consent was taken from the owner of the animals before treating them. There is no specific law in India that requires permission from ethics committee for collecting milk samples and treating the animals presented to veterinary hospitals by a qualified veterinarian.

\section{Acknowledgement}

The authors are thankful to the Kerala Veterinary and Animal Sciences University for providing the facilities needed for carrying out the research.

\section{References}

Akova, M., 2008. Sulbactam-containing $\beta$-lactamase inhibitor combinations. Clin. Microbiol. Infect. 14: 185-188.

Amrithapriya M. G. 2019. Clinico-therapeutic studies of bovine mastitis caused by Staphylococcus aureus and its molecular typing. MVSc thesis, Kerala Veterinary and Animal Sciences University, Pookode, 154p. 
Bansal, B. K. and Gupta, D. K. 2009. Economic analysis of bovine mastitis in India and Punjab- A review. Indian J. Dairy sci. 62: 337-345.

Barrow, C. I. and Feltham, R. K. A. 1993. Cowan and Steel's Manual for the Identification of Medical Bacteria.(3rdEd.). Cambridge University Press, Great Britain, 331p.

Bauer, A. W., Kirby, M. M., Serris, J. S. and Turck, M. 1966. Antibiotic susceptibility testing by a standardized single disc method. Am. J. Clin. Pathol. 45: 493-496.

Charaya G., Kumar A., Sharma A., Singh M. and Goel P. Comparitive efficacy of Tylosin, Enrofloxacin and Ceftriaxone in treatment of buffaloes suffering from mastitis. Haryana Vet. 54: 154- 156.

Clinical and Laboratory Standards Institute. 2017. Performance standards for Antimicrobial Susceptibility testing (25 $5^{\text {th }}$ Ed.). Clinical and Laboratory Standards Institute, Wayne,15p.

Dasohari, A., Somasani, A. and Nagaraj, P. 2017. Therapeutic management of sub clinical mastitis in cows. The Pharma Innovation. 6: 198.

Dhanda, M.R. and Sethi, M.S. (1962). Investigation of mastitis in India. ICAR Res. Series No. 35. New Delhi, India.

Kaartinen, L., Löhönen, K., Wiese, B., Franklin, A. and Pyörälä, S. 1999. Pharmacokinetics of sulphadiazine-trimethoprim in lactating dairy cows. Acta. Vet. Scand. 40: 271-278.

Kalmus, P., Aasmäe, B., Kärssin, A., Orro, T. and Kask, K., 2011. Udder pathogens and their resistance to antimicrobial agents in dairy cows in Estonia. Acta. Vet. Scand. 53: 1-.4.

Kasravi, R., Bolourchi, M., Farzaneh, N., Seifi, H.A., Barin, A., Hovareshti, P. and Gharagozlou, F. 2010. Relationship between in vitro antimicrobial sensitivity of bovine subclinical mastitis isolates and treatment outcome in lactating dairy cows. Iranian J. Vet. Res. 11: 249-254.

Kulangara, V., Nair, N., Sivasailam, A., Sasidharan, S., Kollannur, J. D. and Syam, R. 2017. Genotypic and phenotypic $\beta$-lactam resistance and presence of PVL gene in Staphylococci from dry bovine udder. PloS one. 12 p.e0187277.

MacDiarmid, S.C., 1978. Antibacterial drugs used against mastitis in cattle by the systemic route. N. Z. Vet. J. 26: 290-295.

Quinn, P., Markey, B., Carter, M. and Carter, G. R. 2013. In: Clinical Veterinary Microbiology. (2nd Ed) Mosby, St. Louis, $514 \mathrm{p}$.

Rathish, R. L. 2014. Clinico- therapeutic studies and experimental evaluation of a bacterin against common bacterial isolate of bovine mastitis. PhD thesis, Kerala Veterinary and Animal Sciences University, Pookode, 177p.

Sebastian, S, R. (2001). Clinico-therapeutic studies on bacterial etiology of bovine mastitis. M.V.Sc thesis, Kerala Veterinary and Animal Sciences University, Pookode, 57p.

Singh, K.P., Singh, R.V., Singh, P., Singh, S.K. and Singh, J.P. 2015. Comparative evaluation of antimicrobials for therapeutic management of bovine mastitis. Intas Polivet. 16: 261-264.

Xin, X., Jian, L., Xia, X., Jia, B., Huang, W., Li, C., Wang, C., Zhou, L., Sun, X., Tang, X. and Huang, Y.2013. A multicentre clinical study on the injection of ceftriaxone/ sulbactam compared with cefoperazone/ sulbactam in the treatment of respiratory and urinary tract infections. Ann. Clin. Microbiol. Antimicrob. 12: 38-47. 